\title{
INTIMATE LANGUAGE STYLE IN NICHOLAS SPARKS' MOVIE SCRIPT THE NOTEBOOK
}

\author{
Annisa Oktaviani, Purwarno Purwarno \\ Faculty of Literature, \\ Universitas Islam Sumatera Utara (UISU), Medan, Indonesia \\ E-mail: annysa238@gmail.com
}

Received: 2021-04-24

Accepted: 2021-05-27

\begin{abstract}
This research is aimed at analyzing the intimate language style used by the characters in Nicholas Sparks' movie script, The Notebook. In this research, the characteristics of the intimate language style used by the characters and the factors that influence these figures using intimate language styles in the movie would be revealed. The researchers apply a descriptive qualitative design. The research data are in the forms of film transcripts. The main theory used in this research is the theory proposed by Martin Joos. The results show that the researchers find 22 intimate language style utterances. In detail, the 22 intimate language style utterances include Addresse with 6 data, Extraction with 4 data, Jargon 3 data, Close relationship with 5 data, and Family relationship with 4 data. In addition, it is also found that there are four social factors that influence the characters to use intimate language styles. The first factor is the participants. The film's participants have very close relationships such as Family members or Close friends. The second factor is topic. The topics discussed in this film are privacy and love. The third factor is setting. Conversations in the film are often completed in several informal and private places such as beaches, houses and so on. The fourth factor is function. The speech functions produced by these characters vary; however, most of them have the same aim; that is to convey or show their intimacy to each other.
\end{abstract}

Keywords: intimate language style, addressee, extraction, jargon.

\section{Introduction}

Language is central to social interaction in every society, regardless of location and time period. Language and social interaction have a reciprocal relationship: language shapes social interactions and social interactions shape language. In the society people use language to communicate with each other. As human beings, we need language to express our feeling, ideas, emotions, and thoughts to people by using sound, gesture and signal that have pattern. Language is both a system of communication between individuals and a social phenomenon. The area of language and society is intended to show how our use of language is governed by such factors as class, gender, race, etc.

There are many experts that have different statements about kind of language style. The most famous expert who has the statement about language style is Martin 
Joos. In his book under the tittle The Five Clocks (1976), he explains that language style can be divided into five types: frozen, formal, consultative, casual, and intimate language styles.

Based on Joos' five types of language styles, the writers focuses the research on intimate language style. Intimate language style is the most casual style in communication. It is usually used between family members, close friends, couple, and all of relations that show intimacy. According to Joos (1976: 155), intimate language style is an utterance to avoid giving the addressee information outside of the speaker's skin.

In this study, the researchers analyze the characteristics of intimate language styles used by the characters in The Notebook movie and the factors influencing the characters using intimate language style based on the theory proposed by Joos (1976). Besides, the researchers also apply the theory of social factor proposed by Holmes (1992) to know the factors that make the characters use intimate language styles in their utterances.

\section{Literature Review}

As mentioned earlier, one of the two kinds of language variety based on the use is style. Language style is the choice among the other alternatives in using language (Ducrot and Todorov: 1993). There are some factors, which influence language to have variations. Region, social status, and culture play roles to make language variation. Besides, the language itself, which is used for many purposes such as business, education, newspaper and many more, also play roles to make the language have variations and styles. According to Hudson (1996: 2) in Sulistyorini (2008) a variety is a set of linguistic items with the sense of mutual intelligibility, which means that among people who are in communication with one another they will understand each other. The variation of language can be seen from the form of language, vocabulary, grammar, style, etcetera. In this research, the language variation that will be observed is speech style based on degree of formality. The formality would be viewed from the form, grammar and vocabulary in the utterances produced by the characters of The Notebok Movie.

\subsection{Speech Style}

Speech style is the form of language that a speaker uses and it is characterized by the degree of formality ( Joos, 1976: 156). The analysis of English style is offered by Martin Joos in his strangely tittled book, The Five Clocks (1962). The 'clocks' are levels of formality in spoken and written english, which Joos labels 'frozen', formal', 'consultative', 'casual', ' intimate' (Coupland, 10: 2007). The speech style help the speaker to choose the suitable style when they are talking. It will help the speaker deliver a speech more effectively. Labov in Bell (2007: 91) devises means for eliciting different styles of speech from people within compass of single interview. As well as seeking answer to questions, the interviewer has informants carry out several language tasks, designed to focus increasing amouth of their attention on how they are speaking.

\subsubsection{Frozen Style}

Frozen style is speech style that is usually used in very formal situation. The characteristic of pronounciation is monotone. It called "Frozen" because it already has a pattern and cannot be changed. In writen language, frozen syle can be found in 
historical documents, laws, anthems, bible, and marriage ceremonies. Frozen style has a long sentence than the others. The utterance of this style must be accepted seriously by the listener. Frozen style is more elaborated than the other style. It is structured in planned over still longer spans, often-whole declamation (Sulistyorini:10).

The examples of this style:

"Your voice can change the world"

"We are all one nation"

\subsubsection{Formal Style}

This style is usually used in literary book, president speech,etc. The pattern is standarized and cannot be changed individually. For the patterns, it seems like a standard language that only used in formal situation. So, for conversation between friends, it do not use this kind of language style. The vocabulary is also more extensive. This style is usually used in speaking to medium or large groups. The speaker must plan ahead, framing whole sentences before they are delivered. It is also used in speaking to a single hearer.

The examples of formal style:

"Mr. Edward, do come in.."

"Please take a seat, your Majesty"

"How are you, Mr. Jacob, nice to see you"

\subsubsection{Consultative Style}

Based on Joos theory, Chaer explains (2007) this style which is often used in conducting business or discussion. It is such kind of language used in the meeting, at school, or in the production meeting. This style can be used in formal situation and informal situation. In consultative style, pronounciation is explicit. Word choice is careful and sentence structure is complete but the sentence tends to be shorter and less well planed. The speaker constantly watches the listener's verbal and non verbal responses in order to decide whether too much or not enough information is being transmitted. Chaer (2001) explains that this style is the most operational among other styles.The listener usually respons to the speaker by simple signal, " uh, I see, well, Mr. Lionel, I think it's good".

\subsubsection{Casual Style}

Casual style is an informal communication between friends and insider who have something or background information to share. When people use this language, it is usually shortened so that we can find this style in chats, phone calls and daily conversation. The vocabularies are full with dialect, regional dialect and seldom use proper structural morphology and syntax. Anothercharacteristic of this style is sometimes the sentence is less on grammar.This style is used for relaxed situation such as with close friends, acquaintances, insiders in social setting.

The examples of casual style :

"Comin' over tonight? Be there at eight"

"What's up man?"

"Freaking out" (getting scared) 


\subsubsection{Intimate Language Style}

Intimate language style is usually used by participants who have very close relationship, like between family members, between close friends. This language can be identified by the use of incomplete language, short words, and usually with unclear articulation. This happens because participants have already understood each other. This style is characterized by what Joos calls "extraction". In this style, intonation is important than wording or grammar. The speaker sometimes uses private vocabulary. As Joos explains that intimate style is characterized by a stable list of words with private meanings shared only by a small group- usually in pair, in family situation.

The examples of Intimate style:

"You have to believe me, Dear",

"Just try to be brave as your father, boy",

"Betty, you can do this, talk to me as friend"

\subsection{Characteristics of Intimate language Style}

According to Joos (1976: 157), there are five characteristics of intimate language style, namely addressee, extraction, jargon, close friend relationship, and family relationship.

\subsubsection{Addressee Characteristic}

Addressee is the first characteristic. The speaker's relationship to the addressee is crucial in determining the appropriate style of speaking. The better addressor and the addressee know each other the more informal language style that they use. On the opposite, if the addressor and the addressee do not know each other well, they will use the more formal speech style. However, both of the participants have close relationship. The example of addressee is Dad, Mom, Honey, special nickname, and so on.

Examples:

Allie : "Yes, Daddy I love him"

Allie's Daddy : "He is not suitable for you baby"

The Notebook Movie (2004)

\subsubsection{Extraction Characteristic}

The second characteristic is extraction. Extraction happens when the speaker extracts a minimum pattern from some casual sentence. Sometime, people use incomplete sentence in their conversation, but the hearer still can get what is the purpose of speaker utterance. In this occupation, the participants of conversation have close relationship, so both speaker and hearer can easily understand about the purpose of the conversation.

Example

Alex : Yeah, yeah...

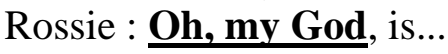

Alex : Is that? Bethany?

\subsubsection{Jargon Characteristic}

The third characteristic is Jargon. Jargon is a type of shorthand between members of a particular group of people, often with words that are meaningless outside of a certain context. Jargon is technical vocabulary associated with special activity or 
group. Jargon is used to show the secret language on the several circumstances. In other words, jargon must not be understood by other people. Examples:

Alex : For a minute there, I thought you might be in love with me or something.

Rossie : Alex, you will forever be the boy. Who wiped bogeys on my favourite party dress, OK?

Alex : Don't flatter yourself

\subsubsection{Close Relationship Characteristic}

The fourth characteristic is close relationship. Close relationship characteristic is a private language among friends, that the meaning is understandable by close friends that show intimacy. People have their own way to convey something to their close friends. In this case, the topic being discussed is usually an informal thing like love, life and sometime about a secret known only by close relationship.

Example

Allie : "I need you to tell him that I love him and tell him that I'm sorry for everything, okay?"

Fin : "Look I was up all night with him, Allie. I've never seen him so low. It's over don't make it any harder than it already is"

\subsubsection{Family Relationship Characteristic}

The fifth characteristic is family relationship. This characteristic occurs among family. This characteristic is almost the same as close friend characteristic. The difference lies on the participants of the conversation. Participants in this characteristic are family members.

Examples:

Allie's Dad :"Allie..."

Allie : 'Daddy, Oh Daddy you are. I did not see you there. You kinda scared me.

Allie's Dad : "Becoming friendly with that boy down there"

Allie : "Yes"

Allie's Dad : "Bring him to the house on Sunday. I want to meet this young man"

Allie : "Okay, Good Night, Daddy"

\section{Research Method}

In this study, the researchers use descriptive qualitative method as the researchers analyze the data in the form of words descriptively. Therefore, the qualitative is the appropriate method to complete this research because the researchers do not use the numeric or statistic forms in data analysis. Qualitative research is used to describe and analyze what usually happens in daily activities. In addition, descriptive research is used to obtain information about existing conditions. Creswell (1994: 1) states that the qualitative research is an inquiring process of understanding a social or a human problems in a natural setting. Then Bogdan and Biklen (1998:77) states that in qualitative research, the human investigator is the primary instrument for the gathering and analyzing the data. The research needs data. A researcher gets the data from the movie entitled "The Notebook". The primary data of this research are the characters" utterances suggesting intimate language style. Data sources of this research are movie transcripts. 


\section{Discussion}

\subsection{The Characteristics of Intimate Language Style}

In this part, the researchers analyze the data of intimate utterances which are produced by the characters of the movie based on Joos' (1976: 155) theory of speech style in which he claims that intimate language style has five characteristics: Addressee, Jargon, Extraction, Close Friend Relationship, and Family Relationship.

\subsubsection{Addresse}

The first characteristic of intimate language style is addressee. This characteristic takes place when the speaker produces the utterances which are directed to a certain person. People who have close relationship usually have a special addressee such as Dad, Mom, Honey, and so on. The various examples of the intimate language used by the characters of the movie are presented below.

Data 1

Sara : "Hi Fin!"

Fin : "Hi Honey, look I won you a prize"

Sara : "Oh...Fin, thank you"

The conversation above occurs between Fin and Sara, and the setting is at Carnaval. In the conversation, Fin wants to show something (doll) to Sara, his girlfriend. Fin says "Hi Honey, look I won you a prize". This utterance is categorized as addressee characteristic since Fin calls Sarah with special name, "Honey". Fin uses the special name "honey" because Sara is his girlfriend. Therefore, it shows that both of the characters have close relationship.

Data 2

Allie : "Yes, Daddy I love him"

Allie's Daddy : "He is not suitable for you baby"

The conversation above happens at home when Allie argues with her father. She tells her feeling to her father, and calls her father by using the word "Daddy", and in the same case, his father also uses the word "baby" to call her daughter, Allie. Both Allie and her father use the intimate language style to address each other. That is why the data is categorized addressee characteristic because the utterance contains lovely call.

\subsubsection{Extraction}

Extraction occurs when the speaker extracts the minimum pattern or produces incomplete sentence in their utterances. This characteristic often appears when people talk about secret. The various intimate styles with extraction characteristics are presented below.

Data 1

Allie : "Say I'm a bird"

Noah : "No, Don't do it"

Allie : "Say I'm a bird"

Noah : "Stop it, stop it now, you are not"

Allie : "Say it"

Noah : "You are a bird" 
The conversation takes place when Allie asks Noah to enjoy the beach and the wave. When Noah asks Allie, "what are we doing?", Allie thinks about their life in another life. Allie says, "Say I'm a bird" and forces Noah to say she is a bird. This extraction does not reduce the full message of conversation because the interlocutor can catch the full meaning of the speaker. It occurs among close friends who have an intimacy in relationship. Therefore, this utterance is called intimate style with extraction characteristic.

Data 2

Allie : : Oh My God Mama"

Allie's Mom : "Yeay..!"

The conversation above happens in the restaurant when Lon is with Allie's parents, and he is proposing Allie to marry him. Allie accepts Lon's proposal, and everyone is so happy at the time. Allie is screaming to her mother by expressing " $\mathrm{Oh}$ My God Mama", and her mother who knows about the proposal can understand the purposes of her utterances and she happily welcomes his daughter and gives her a hug. This extraction does not reduce the full message of the conversation because the listener can catch the full meaning of the speaker. It occurs among family members who have an intimacy in relationship.

\subsubsection{Jargon}

Jargon is type of language that is used in a particular context and may not be well understood outside that context. The data of the intimate styles with jargon characteristics used by the characters of the movie are presented below.

Data 1

Allie : "Oh hell, well if you're going to do it..."

Noah : "Come here"

Allie : "No, don't touch me"

The conversation above occurs when Allie is getting angry at Noah. Noah tries to persuade Allie, but Allie still gets angry and says, "Oh hell, well if you're going to do it..." The dialogue above is categorized as jargon characteristic. It is clearly seen when Allie says, "Oh. Hell". The utterance above shows an intimacy since Allie says the word "hell" which actually implies another meaning that the word "hell" really means. In other word, the word "hell" is not the real meaning (a place regarded in various religions as a spiritual realm of evil and suffering), but it implicitly describes the worst condition.

Data 2

Allie : "Mama, look, the Governor's coming."

Allie's Mom : "He better. Let me see. Oh, boy."

The conversation above occurs when Allie is fitting on her wedding dress with her friends and her family members. When her friends and family members show her the latest news about her wedding, Allie's mother takes the newspaper. In fact Allie reads another newspaper that her mom is surprised and says, "oh.boy". In other words, the word "oh boy" is not the real meaning (a male child or young man), but it implicitly describes "God". 


\subsubsection{Close Relationship}

Close Friend Relationship is a private language among friends, between a boyfriend and girlfriend and also life partners that the meaning is understandable by close relationship. The data of the intimate style with close relationship characteristics are presented below.

Data 1

Allie : "I need you to tell him that I love him and tell him that I'm sorry for everything, okay?"

Fin : "Look I was up all night with him, Allie. I've never seen him so low. It's over don't make it any harder than it already is"

The conversation above happens at the lumber yard, the place where Noah works. Allie wants to meet him because she will go to New York and leave the town, but she does not meet him so she meets Fin and tells everything about what happens the night before. The dialogue above employs intimate style with Close Relationship characteristic. It is proved when Fin says, "Look I was up all night with him, Allie. I've never seen him so low..." It explains how his friend, Noah is so low.

Data 2

Allie : "You saying you want to break it off?"

Noah : "What I'm saying we see how it goes later on"

Allie : "Are you breaking up with me?"

Noah : "I don't see, how it's gonna work"

Allie : "I see...Please don't do this."

The conversation above happens in Allie's Yard when Allie's Parent disagrees about the relationship between Allie and Noah because Noah is a poor man that he is not suitable for Allie, who is wealthy. The dialogue above employs intimate language style with close relationship characteristic. It is proved when Allie says, "Are you breaking up with me?". That sentence shows that Noah and Allie have close relationship for long time. Therefore, this utterance is called intimate language style with close relationship.

\subsubsection{Family Characteristic}

The last characteristic is Family relationship. This characteristic occurs between family members. The language of the conversation is informal among family relationships.The various examples of intimate style with family relationships are presented below.

Data 1

Allie's Dad : “Allie.!"

Allie : "Daddy. Oh, Daddy you're...I didn't see you there. You kinda scared me"

Allie's Dad : "Becoming friendly with that boy down there"

Allie : "Yes"

Allie's Dad : "Bring him to the house on Sunday I want to meet this young man"

Allie : "Okay, Good Night Dad"

Allie's Dad : "Good Night"

The dialogue above happens in Allie's House. This conversation occurs between the father and his daughter. When Allie comes home late at night and her father talks to 
her about the man who becomes friendly with his daughter. The dialogue above is categorized as family characteristic. It can be seen when father "Bring him to the house on Sunday I want to meet this young man", in this statement her father wants to know about the boy who is close to his daughter because her father is afraid if Allie falls in love with the wrong guy.

Data 2

Allie's Mom : "That child's got too much spirit for a girl of her circumstance"

Allie's Dad : "Nah, it's just summer love"

Allie's Mom : "Trouble is what it is"

The dialogue above happens in Allie's garden. This conversation occurs between his parents that worry if Allie takes his relationship with Noah seriously but her dad says "Nah, it's just summer love". His parents really disagree about that because Noah is poor and they are worried the one and only their daughter will have bad future. The dialogue above is categorized as family characteristic.

\subsection{Factors Influencing the Characters to use intimate style}

After knowing the characteristic of intimate style of the characters in the movie to communicate with interlocutor, the researchers explore the factors that influence the characters to use intimate language style. To reveal this case, the researchers consider the social context which is involved inside the communication. The researchers notice three aspects influencing the characters using intimate style based on Holmes theory. As stated by Holmes (1992:1), the way people talk is influenced by the social context. It involves who can hear us and where we are talking, as well as how we are feeling towards our interlocutor. The social factors are Participants, Topic, Setting and Function.

The first factor is Participant. Almost all of the characters are involved in conversation with intimate language style. Allie and Noah have very close relationship. They always understand about what are their talking about. Even sometimes they are using incomplete sentence, jargon, or something different, they can understand each other. This case indicates that there is a good comprehension between the speaker and interlocutor that causes the intimate style. The examples when Noah says "Would you stop thingking about what everyone wants? Stop thingking about what I want, what he wants, what your parents want. What do you want? What do you want?" Noah repeats the question "What do you want?" And it feels so basic. In life, most of us often forget one important thing. That is to be ourselves, to be what we want to be. We're busy acting out who they want to be, being what they think is good for us, becoming what we don't want to be, which ultimately leads us to unconsciously choose what they want us to choose. Oh well, if that's the case, then our lives are a lie."

On the other hand sometimes they use incomplete sentences to show their feelings, but the interlocutor or hearer can easily understand. The examples are when Allie's Mom says "Allie...Here, I hope you make the right choice." although her Mom completes her utterance, Allie can understand the purposes of her mother's utterances.

The second factor is Topic. This factor has an important impact because it tells what is being talked and discussed about. It relates with the relationship and interaction among participants. This kind of relationship can impact the topic that they are talking about. It can be seen when Noah explains to his daughters about his feelings toward 
their Mom Allie. He says 'Look guys, that's my sweetheart in there, I'm not leaving her this is my home now. Your mother is my home". This conversation can be classified as intimate language style because the topic is about love or intimacy.

The third is setting. This factor also has a big influence on intimate style use. Holmes (1992:30) states that setting is related to the way people select an appropriate code or variety. For example when Noah is teasing Allie in the street saying "Yeah, sure, Mr. Underwear, was it?", he uses the word underwear without the real meaning of underwear but more like the word "the weird guy". That utterance can have different meaning when the setting is not in the street (informal situation), for example in the market the word underwear can have the real meaning. From this example, we know that different places or settings can make the meaning of the sentences change.

The fourth factor is function. The functions of the utterances produced by the characters are varied because they have different purposes in different utterances. However when one employs intimate language style, the function of the utterances is to show their intimate relationship. For example when Noah's Dad says "I Love you" to his son, the function of this utterances is to show that the father loves his son.

\section{Conclusion}

The researchers manage to prove that the characters of the movie truly use intimate language style in their conversation. In the movie, the characters produce five characteristics of intimate language style such as addressee, extraction, jargon, close relationship, and family relationship. There are 22 utterances that contains intimate language style. There are six (6) utterances of addressee characteristic, four (4) extraction, three (3) jargon, five (5) Close Friend Relationship, and four (4) Family Relationship Characteristic. Dealing with the second research question, there are four social factors that influence the characters to use intimate style. The first factor is participant. The participant of this movie has very close relationship such as family member or close friend. Close relationship is an aspect of using intimate language style. The second factor is topic. The topic discussed in this movie is about private topics, deep, and sometimes talking about love. The third is setting. The conversation in the movie is often settled in some informal and private places such as beach, house and so on. The fourth is function. The function of the utterances produced by the characters are various. But most of them are to convey or to show their intimacy on each other.

\section{References}

Bell, Allan. (1984). Language style as Audience Design. Language in society. Cambridge. University Press.

Bogdan, R. C and Biklen S.K.B. (1998). Qualitative Research for Education to Theory and Methods. California: Allyin and Bacon Inc.

Chaer, Abdul \& Agustina, Leonie. (2004). Sosiolinguistik Perkenalan Awal. Jakarta: RINEKA CIPTA

Coupland, Nikolas. (2007). Language Variation and Identity Key. Cambridge. University Press

Cresswell, J. W. (1994). Research Design Qualitative and Quantitative Approach. London: Sage Publications.

Ducrot and Todorov. (1993). Introduction to Language Style. London. Cambridge University. 
Holmes, J. (1992). An Introduction to Sociolinguistics. New York: Longman Publishing.

Joos, Martin. (1976). The Style of Five Clocks Ed. Nancy Ains Worth Johnson, current Topics in Language: Introductory Reading. Massachusetts.

https://dailywritingtips.com/lingusitic-register-and--code-switching/ (May 2020).

Sparks, Nicholas. (2016). The Notebook. https://nicholassparks.com/stories/thenotebook/.

Sulistyorini. (2008). The Speech Style of TV cosmetic commercials and The Attitude of Woman TV Watchers toward the Commercials. Surabaya: English Department, Faculty of Arts, State University of Surabaya. 